\title{
Three-dimensional Simulation on Behavior of Water Film Flow with and without Shear Stress on Water-Air Interface
}

\author{
Y.Q. Yu ${ }^{\mathrm{a}, \mathrm{c}+}, \mathrm{X}$. Cheng $^{\mathrm{a}, \mathrm{b}}$ \\ ${ }^{a}$ School of Nuclear Science and Engineering,Shanghai Jiao TongUniversity, Shanghai 200240,China \\ ${ }^{b}$ Institute for Nuclear and Energy Technologies Research Center Karlsruhe, Karlsruhe 76021, Germany \\ ${ }^{c}$ Nuclear Engineering Division, Argonne National labortary, Lemont,IL 60439, United State
}

\begin{abstract}
In this paper, the simulations of falling film behaviour on a flat plate with and without interfacial gas-liquid shear stress were carried out. A three-dimensional numerical model was established based on film flow characteristics. A source term was implanted into the numerical model to take into account the interfacial gas-liquid shear stress. The model was validated by the experimental data. Both continuous film flow and film breakup were simulated. The film thickness, velocity distribution and wall shear stress at different Reynolds numbers were presented to understand the film flow behaviour comprehensively. The influence of water-air shear stress on film flow behaviour was revealed. A reasonable prediction on both MWR (Minimum Wetting Rate: $\Delta_{\min }$ ) and MLFT (Minimum Liquid Film Thickness: $\Gamma_{\min }$ ) were obtained. The model proposed in this study ought to be profitable for studies on mechanism of film breakup.
\end{abstract}

Key words: falling film, solitary wave, flat plate, MWR, MLFT.

\section{Introduction}

Film flow is widely applied in many industrial fields due to its high thermal efficiency and low flow rate. The application in Passive Containment Cooling System (PCCS) of Generation III nuclear power plant AP1000 is one of them. Driven by gravity in PCCS, the water from a storage tank is poured on the containment and forms a film over it during the accidents. The film flow on the containment plays a significant role on decay heat removal. In the meantime, the nature convection in PCCS can cause gas-liquid shear stress on the free surface of the film flow. Due to large diameter of the containment, the film flow on the containment can always be considered as film flow on a flat plate.

Film flow has been extensively studied for several decades. Although current measuring techniques have been improved considerably, the experimental studies on film flow are still confined in measurement of wave velocity, wave length, and film thickness. The flow field inside film flow is difficult to measure due to the tiny scale of film thickness. Consequently, numerical study becomes a promising way to provide better understand on flow behaviour inside the film. Nusselt (1916) proposed a laminar model for film flow. The model assumes that film flow is laminar with smooth surface and the shear stress on the interface is 0 . The Navier-Stokes equation for film flow can be expressed as follows:

$$
\rho \frac{D U}{D t}=-\nabla P+\rho g+\mu \nabla^{2} U
$$


According to the assumption of Nusselt theory:

$$
\begin{gathered}
U_{x}=U_{y}=0 \\
\frac{\partial U_{z}}{\partial z}=0
\end{gathered}
$$

Where $\mathrm{z}$ is the direction of film flow, $\mathrm{x}$ is the width direction and $\mathrm{y}$ is the direction of film thickness, $\mathrm{U}$ is the velocity of film flow, $\mu$ is the molecular viscosity.

The equation 1 can be simplified with equation 2 and equation 3 :

$$
\mu \frac{d^{2} U_{z}}{d y^{2}}=-\rho g
$$

No slip wall and no interfacial sheer stress boundary condition can be expressed as follows:

$$
\begin{array}{ll}
y=0, & U_{z}=0 \\
y=\delta, & \frac{d U_{z}}{d y}=0
\end{array}
$$

Where $\delta$ is film thickness. A parabolic velocity distribution inside film flow can be obtained by substituting equation 5 and equation 6 for equation 4 :

$$
U_{z}(y)=\frac{\rho g \delta^{2}}{2 \mu}\left[\frac{2 y}{\delta}-\left(\frac{y}{\delta}\right)^{2}\right]
$$

Based on the principle of mass conservation, velocity distribution and definition of Reynolds number of film flow (equation 8), the relationship between film thickness and Reynolds number can be obtained in equation 9 .

$$
\operatorname{Re}=\frac{4 \Gamma}{\mu}
$$

Where $\Gamma$ is the linear mass velocity $(\mathrm{kg} / \mathrm{m} \cdot \mathrm{s})$, Re is Reynolds number and $v$ is the dynamic viscosity of film flow $\left(\mathrm{m}^{2} / \mathrm{s}\right)$.

The instability is one of the most significant characteristic of film flow, which leads to the production of surface waves. When film is falling down, it is influenced by small disturbances which will gradually develop to large surface waves. Generally speaking, film flow consists of film substrate and surface wave which is also referred to as solitary wave. The fluid in the film substrate is laminar while the fluid can be turbulent in the solitary wave. Most theoretical studies are based on smooth surface assumption, the fidelity of which is poor. In recent years, Computational Fluid Dynamics(CFD) method has achieve some success on modelling a wide range of industrial applications, such as water-vapor flows in PWR/BWR, gas-solid fluidization, gasification, etc.(Tentner, et.al., (2014), Vegendla, et.al,(2011a,2011b) , Vegendla, et.al.,(2012)). Among the numerical studies, CFD is of higher fidelity to describe the film flow behaviour in spite of its considerable computational cost. Fortunately, it becomes realizable with the development of computers in recent decades.

Kheshgi and Scriven (1987) solved two dimensional Navier-Stokes equations to analyse the stability of film flow on a flat plate. The results showed that the disturbances fade away when wave length of the disturbance is smaller than some critical wave length. Otherwise, the disturbances will develop to steady waves. The large disturbances may probably lead to the 
decomposition of the wave and the film breakup, which agree well with other linear numerical results through solving Orr-Sommerfeld equation. CFD study (Maron, et.al.,(1989)) also indicated that the velocity distribution in capillary wave is similar with that in solitary wave. The vortices inside the solitary wave are formed when the surface velocity of the wave crest exceeds the wave velocity with the increase of the wave amplitude. It is also pointed out that the forming of the vortices requires the ratio between solitary wave height and substrate thickness to be over 2.5. Stuhlträger et.al.,(1995) studied the effect of surface wave on heat transfer with CFD method. The numerical results revealed that the heat transfer coefficient is enhanced due to the decrease of the average film thickness. The time-averaged temperature presented linear distribution in film thickness direction. Serifi et.al.,(2004) simulated the film flow on an inclined flat plate. The thermal hydraulic characteristics of film flow were analysed. The research pointed out two main factors which enhance the heat transfer of film flow. One is the decrease of substrate thickness and the other is convection effect in wave crest and tail. Tomoaki and Chiaki's (2003) CFD calculation found out that the heat transfer of film flow can be enhanced by introducing artificial disturbance. Miyara (1998, 1999, 2000) performed the CFD simulation on solitary wave with low Reynolds number. The research found out that the recirculation zone in the solitary wave intensifies the heat transfer between film and wall. The research also indicated that scale of the vortices increase with Reynolds number. Jayanti and Hewitt (1997a, 1997b) studied the characteristics of solitary waves with CFD tool. The waves of three typical shapes were investigated, which is sinusoidal wave, twisted sinusoidal wave and solitary wave respectively. The results indicated that there is no recirculation zone under the wave for sinusoidal wave with small amplitude. As for sinusoidal wave with larger amplitude, the heat transfer coefficient is enhanced due to the thinner effective film thickness. The research also pointed out that the fluid in the substrate keeps laminar while the fluid in solitary wave is turbulent with strong turbulent diffusion. Gao et.al.,(2003) used VOF (Volume Of Fluid)-CSF (Continuum Surface Force) method to simulate the free falling film flow under single frequency disturbance. The results confirmed the existence of vortices inside the solitary wave. Sutalo et.al.,(2006) used ANSYS-CFX to simulate the non-Newtonian film flowing along an inclined plate. The calculated film thickness and film shape agree well with the experimental data.

CFD method requires solving huge amounts of nonlinear equations. Therefore, most CFD studies of film flow are two-dimensional. Only modest three-dimensional simulations on film flow were developed. Yoshida's et.al.,(2006) predicted both the average film and the evolution of the solitary waves well with three dimensional CFD model. The calculated probability density function (PDF) of film thickness agrees well with the experimental data. Haeria and Hashemabadi (2008) studied the effect of film property, inclination and contact angle on film flow with open source CFD tool OpenFOAM. The velocity distribution and shape of film flow are obtained and in good agreement with the measured data. Lakehal et.al.,(2003) applied DNS method to study the thermal hydraulic characteristics of film flow with counter current gas flow. The study indicated that the heat and mass transfer are tightly associated with the surface wave and the liquid-gas shear stress.

From the literature survey mentioned above, most current CFD study is two-dimensional. Many experimental researches have pointed out that film flow shows strong three-dimensional characteristics. Two-dimensional CFD simulations are not capable of predicting these 
characteristics. Thus, three-dimensional simulations on film flow have become a very meaningful research focus. However, among the existed rare three-dimensional simulations, most of them include no validation work or inadequate validation work. In order to achieve a better understanding of flow mechanisms on film flow, which is helpful for evaluating and improving the PCCS as well as other film flow applications, this paper describes a three-dimensional CFD study of falling film flow with and without shear stress on water-air interface. An adequate number of verification and validation work are performed for establishing the numerical model.

\section{Numerical Strategy}

\subsection{Governing Equation}

Water is incompressible Newtonian fluid. The velocity field of film flow on flat plate include three velocity component: $V=(u, v, w)$. The three-dimensional continuity equation for film flow on flat plate is:

$$
\frac{\partial \bar{\rho}}{\partial t}+\frac{\partial \bar{\rho} u}{\partial x}+\frac{\partial \bar{\rho} v}{\partial y}+\frac{\partial \bar{\rho} w}{\partial z}=0
$$

It is worth mentioning that this study applies the homogeneous model. Hence, air and water in whole computational domain are considered as one fluid. There is no velocity difference between two phases. The three-dimensional Navier-Stokes equations for film flow on flat plate are:

$$
\begin{gathered}
\frac{\partial \bar{\rho} u}{\partial t}+\frac{\partial \bar{\rho} u u}{\partial x}+\frac{\partial \bar{\rho} u v}{\partial y}+\frac{\partial \bar{\rho} u w}{\partial z}=-\frac{\partial p}{\partial x}+\bar{\mu} \nabla^{2} u+F_{\sigma x} \\
\frac{\partial \bar{\rho} v}{\partial t}+\frac{\partial \bar{\rho} v u}{\partial x}+\frac{\partial \bar{\rho} v v}{\partial y}+\frac{\partial \bar{\rho} v w}{\partial z}=-\frac{\partial p}{\partial y}+\bar{\mu} \nabla^{2} v-\bar{\rho} g \cos \emptyset+F_{\sigma y} \\
\frac{\partial \bar{\rho} w}{\partial t}+\frac{\partial \bar{\rho} w u}{\partial x}+\frac{\partial \bar{\rho} w v}{\partial y}+\frac{\partial \bar{\rho} w w}{\partial z}=-\frac{\partial p}{\partial z}+\bar{\mu} \nabla^{2} w+\bar{\rho} g \sin \emptyset+F_{\sigma z}
\end{gathered}
$$

where $\mathrm{x}$ axis is in width direction, $\mathrm{y}$ axis is in thickness direction, $\mathrm{z}$ axis is in flow direction, $\phi$ is the angel between the plate and horizontal direction. $\bar{\rho}$ and $\bar{\mu}$ is the mixing density and viscosity of air and water in computing element respectively, which can be calculated as follows:

$$
\begin{gathered}
\bar{\rho}=\alpha_{\mathrm{g}} \rho_{\mathrm{g}}+\alpha_{\mathrm{l}} \rho_{\mathrm{l}} \\
\bar{\mu}=\alpha_{\mathrm{g}} \mu_{\mathrm{g}}+\alpha_{\mathrm{l}} \mu_{\mathrm{l}}
\end{gathered}
$$

where $\alpha_{\mathrm{g}}, \rho_{\mathrm{g}}, \mu_{\mathrm{g}}$ and $\alpha_{\mathrm{l}}, \rho_{\mathrm{l}}, \mu_{\mathrm{l}}$ represents volume fraction, density and molecular viscosity of gas and liquid respectively. Among them,

$$
\alpha_{g}+\alpha_{l}=1
$$

The phase interface phase is traced by solving the continuity equation of volume fraction $\alpha$ :

$$
\frac{\partial \alpha}{\partial t}+\frac{\partial \alpha u}{\partial x}+\frac{\partial \alpha v}{\partial y}+\frac{\partial \alpha w}{\partial z}=0
$$

The position of free surface is where the fluid density changes from gas density to liquid density.

The momentum source term $F_{\sigma}$ takes into account the effect of surface tension. In order to transfer surface tension from surface force to body force, this study uses Brackbill's et.al.,(1992) Continuum Surface Force (CSF) model. The surface intension is calculated with 
the following equation according to CSF model:

$$
\begin{gathered}
F_{\sigma}=f\left|\nabla \alpha_{l}\right| \\
f=-\sigma \kappa n+\nabla_{s} \sigma
\end{gathered}
$$

where $\left|\nabla \alpha_{l}\right|$ is also called delta function, which insure that surface tension only affect flow near the interface. $\nabla_{s}$ represents gradient factor on free surface. Two items in right side of equation 19 represents normal and tangential component of surface tension respectively. $n$ represents normal vector of free surface.

$$
n=\nabla \alpha_{l}
$$

$\kappa$ represents curvature of free surface, which is calculated with equation 21:

$$
\begin{gathered}
\kappa=\nabla \cdot \hat{n}=\frac{1}{|n|}\left[\left(\frac{n}{|n|} \cdot \nabla\right)|n|-(\nabla \cdot n)\right] \\
\hat{n}=\frac{n}{|n|}
\end{gathered}
$$

The contact angle in this study is obtained with Young's equation:

$$
\cos \theta=\frac{\sigma_{s g}-\sigma_{s l}}{\sigma_{l g}}
$$

where $\sigma_{s g}, \sigma_{s l}, \sigma_{l g}$ is solid-gas, solid-liquid and liquid-gas surface tension respectively.

In order to simulate the shear stress between air and film, the source term of drag force is implanted into momentum equations. The momentum source terms consist of gravity, surface tension and drag force:

$$
F_{m}=F_{g}+F_{\sigma}+F_{f}
$$

where $F_{m}$ is the source term of momentum, $F_{g}$ is the gravity, $F_{\sigma}$ is the body force transformed from surface tension and $F_{f}$ is the drag force. Iliuta et.al.,(1997) pointed out that the driving force of film flow is gravity while the driving force of air flow is pressure drop. Therefore, many experiment researches determine the shear stress between gas and liquid from pressure drop. Based on analyses of experimental data, It is suggested that the pressure drop is the function of velocity difference on the liquid-gas interface and drag force factor. Equation 25 is proposed to calculate the pressure drop (Brauner and Maron, 1982).

$$
F_{f}=\frac{\partial P}{\partial z}=\left|\nabla \alpha_{l}\right| f \rho_{g}\left(U_{g}-U_{\text {surface }}\right)\left|\left(U_{g}-U_{\text {surface }}\right)\right|
$$

where $U_{g}$ is air velocity and $U_{\text {surface }}$ is velocity of film surface. $f$ is the drag force factor.

Many researches that focus on drag force factor so far have proposed plenty of correlations for $f$. It But $f$ from different correlations have huge difference. This study applies the following correlation which is extracted from the test data in a rectangle channel to calculate $f$. (Stephan and Mayinger 1992)

$$
f=0.079 R e_{g}{ }^{-0.25}\left(1+115 \delta^{* N}\right)
$$

where $R e_{g}$ is Reynolds number of air. $\delta^{*}$ is dimensionless film thickness. $\mathrm{N}$ is a factor related to the dimensionless equivalent diameter.

$$
\begin{gathered}
N=\frac{3.95}{\left(1.8+3 / D^{*}\right)} \\
\delta^{*}=\frac{\delta}{L_{L}} \\
D^{*}=\frac{D_{h}}{L_{L}}
\end{gathered}
$$


where $\mathrm{L}_{\mathrm{L}}$ is the Laplace length.

$$
L_{L}=\left(\frac{\sigma}{\left(\rho_{l}-\rho_{g}\right) g \sin \varnothing}\right)^{1 / 2}
$$

\subsection{Boundary Condition and Initial Condition}

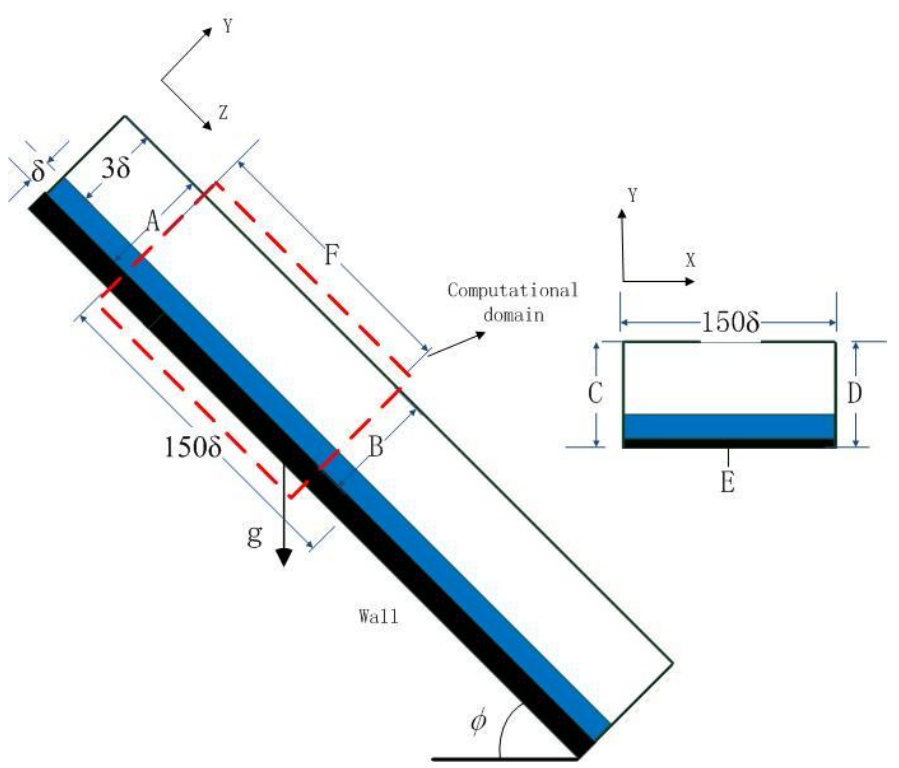

Figure 1 Sketch of the computational domain and boundary condition

If three-dimensional simulation takes the whole flow region as the computational domain, it will lead to a considerable computational cost. This study applies periodic boundary conditions to simulate the fully developed film flow in a relatively short domain $(150 \delta \times 4 \delta \times 150 \delta)$ which is shown in the dotted frame in figure1. The domain contains thin film on a flat plate with air on the top of it. The calculation domain is long enough for one wave length based on the experimental measurement. Boundary A,B and C,D are set as periodic boundary conditions. Boundary $\mathrm{E}$ is set as no slip wall. Boundary $\mathrm{F}$ is set as opening pressure boundary. The initial conditions of the film thickness and velocity are evaluated by Nusselt theory (Equations 7, 9). It is worth mentioning that the choices of the size of the computational domain and the boundary conditions are both based on the film flow characteristics and adequate verification work.

\subsection{Grid Resolution Study and Numerical Scheme}

The hexagonal mesh applied for the simulation is shown is figure2.The mesh near the wall is refined. One of the unique features of film flow is that the characteristic scale in flow direction is much larger than that in thickness direction. The element scale in each direction should be kept as large as 1/10 of the characteristic scale so that the simulation can include all the necessary information. Based on a grid sensitivity study listed in table1, mesh resolution 2 $(1 \delta \times 1 \delta \times 0.2 \delta)$ of 600,000 nodes are selected for the calculation under a comprehensive consideration of the computational cost and the fidelity. 


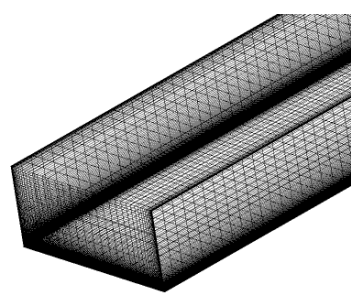

Figure 2 Sketch of the mesh structure

$\mathrm{k}-\omega$ turbulence model is applied to study the turbulence in the solitary wave while low Reynolds model is responsible for dealing with the fluid in the film substrate. The detailed mathematic description of turbulence model can be found in ANSYS-CFX manual (2005). The time step is $1 \times 10^{-4} \mathrm{~s}$. In addition, second order backward Euler scheme and PISO algorithm are applied.

Table 1: Paramters of the Mesh Resolutions

\begin{tabular}{ccccccc}
\hline Sequence & X direction & Y direction & Z direction & Grid number & $\begin{array}{c}\text { Error of } \\
\text { Film Thickness }(\%)\end{array}$ & $\begin{array}{c}\text { Error of } \\
\text { Wall Shear Stress }(\%)\end{array}$ \\
\hline 1 & $1 \delta$ & $0.03 \delta$ & $0.2 \delta$ & 1200000 & 0 & 0.13 \\
2 & $1 \delta$ & $0.05 \delta$ & $0.2 \delta$ & 600000 & 0.11 & 0.32 \\
3 & $2 \delta$ & $0.1 \delta$ & $0.6 \delta$ & 100000 & 0.56 & 0.39 \\
4 & $2 \delta$ & $0.1 \delta$ & $0.8 \delta$ & 75000 & 1.78 & 1.65 \\
5 & $2 \delta$ & $0.1 \delta$ & $1 \delta$ & 60000 & 2.22 & 3.34 \\
\hline
\end{tabular}

\subsection{Specifications of the Problem}

Two test rigs named WABREC (Water Behavior in REctangle Channel) and MICARE+ (MIx Convection Air in REctangle Channel +) were built in Shanghai Jaotong University to study the film flow on a large flat plate. The detailed description of the test rigs is reported by $\mathrm{Yu}$ et.al.,(2012) and Yu and Cheng (2014). This paper uses the data from these two rigs to validate the simulations. In order to enhance the reliability of the simulation, this paper also collects the test data from other research for the validation (Moran, et.al.,2002). The specifications of these cases are listed in table 2. Moreover, some numerical results which are not obtained experimentally are also presented to reveal the mechanisms of film flow.

Table 2: Specifications of the Simulation Cases

\begin{tabular}{|c|c|c|c|c|c|c|c|}
\hline Data Source & $\begin{array}{c}\text { Working } \\
\text { Fluid }\end{array}$ & $\begin{array}{c}\text { Plate } \\
\text { Inclination }\end{array}$ & Re & $\begin{array}{c}\rho \\
\left(\mathrm{kg} / \mathrm{m}^{3}\right)\end{array}$ & $\begin{array}{c}v \\
\left(\mathrm{~m}^{2} / \mathrm{s}\right)\end{array}$ & $\begin{array}{c}\sigma \\
(\mathrm{N} / \mathrm{m})\end{array}$ & $\begin{array}{c}\text { air velocity } \\
(\mathrm{m} / \mathrm{s})\end{array}$ \\
\hline $\mathrm{Yu}$ (WABREC) & water & $90^{\circ}$ & $50 \sim 900$ & 1000 & $1 \times 10^{-6}$ & $7.275 \times 10^{-2}$ & 0 \\
\hline $\mathrm{Yu}($ MICARE+$)$ & water & $30^{\circ} \sim 65^{\circ}$ & $50 \sim 900$ & 1000 & $1 \times 10^{-6}$ & $7.275 \times 10^{-2}$ & 0 \\
\hline Moran,2002 & silicone oil & $45^{\circ}$ & $13 \sim 220$ & 960 & $2 \times 10^{-5}$ & $2.06 \times 10^{-2}$ & $0 \sim 10$ \\
\hline
\end{tabular}




\section{Results and Discussions}

\subsection{Film Thickness}

Average film thickness is one of the important statistical variables of film flow. Figure 3 shows the comparisons of film thickness between the numerical results and the experimental data. It is noticeable that the three-dimensional simulation has better agreement with the experimental data than the two-dimensional simulation and Nusselt theory do. No surface wave is predicted by the two-dimensional simulation while surface wave is well captured by the three-dimensional simulation (figure4). The numerical results of film thickness indicate that it is necessary to develop three-dimensional simulation to reproduce the surface wave.

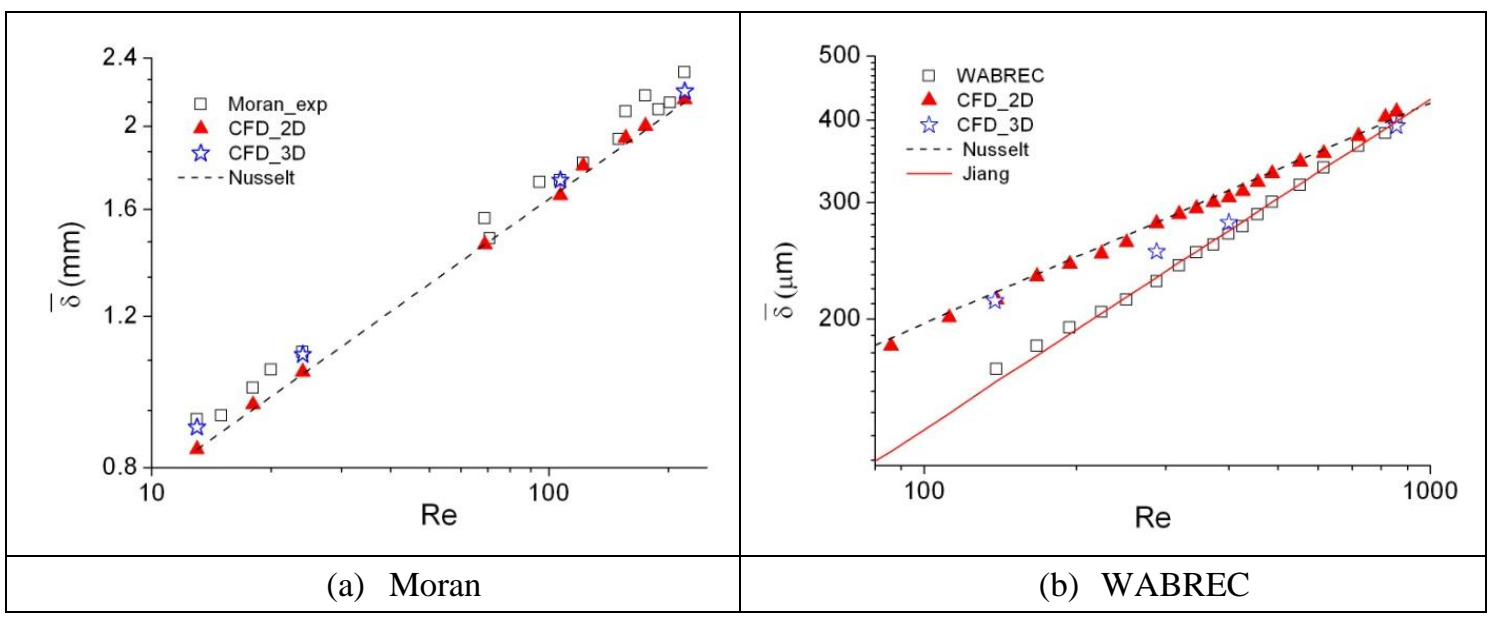

Figure 3 Average film thickness

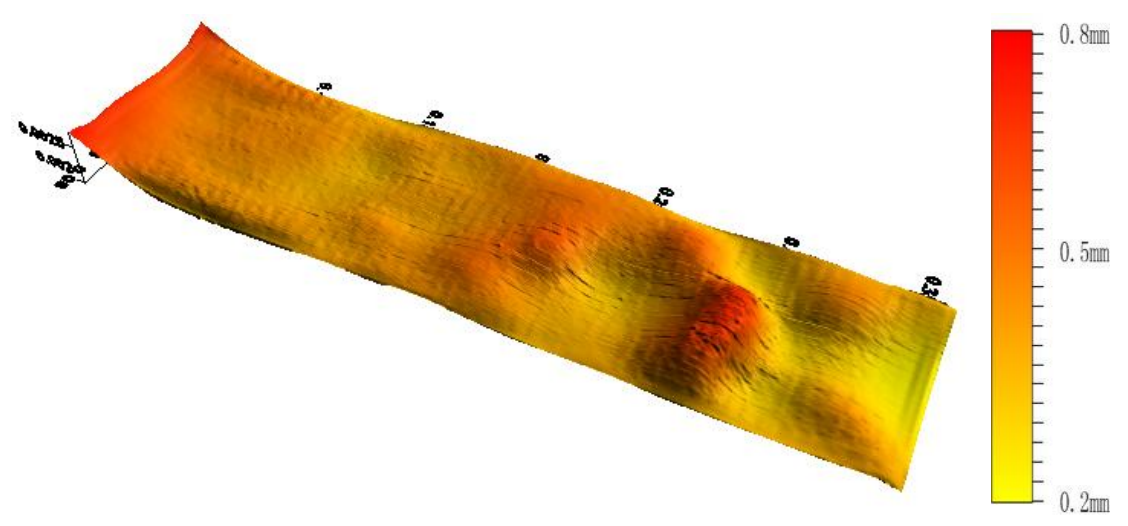

Figure 4 Surface wave of film flow in three-dimensional simulation

It is not difficult to get the equations as follows based on Nusselt theory to predict the film thickness of film flow with interfacial shear stress:

$$
\begin{gathered}
\delta=\left(\frac{3}{4+6 \tau_{i}^{+}}\right)^{1 / 3} R e^{1 / 3}\left(\frac{v^{2}}{g \sin \varnothing}\right)^{1 / 3} \\
\tau_{i}^{+}=\frac{\tau_{i}}{\rho g \sin \emptyset \delta}
\end{gathered}
$$

where $\tau_{i}$ is interfical shear stress $\left(\mathrm{N} / \mathrm{m}^{2}\right)$ and can be estimated with the following equation:

$$
\tau_{i}=\frac{1}{2} f \rho_{g} U_{g}^{2}
$$


and $\mathrm{U}_{\mathrm{g}}$ is air velocity. When $\tau_{i}>0$, the air flow is downward current. When $\tau_{i}<0$, the air flow is counter current.

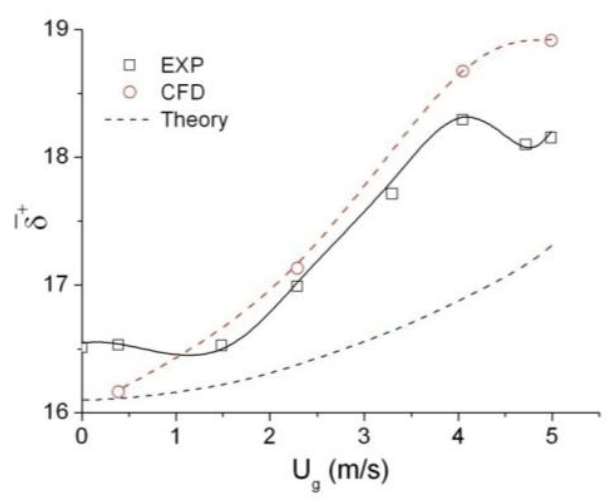

Figure 5 Average film thickness of film flow $(\operatorname{Re}=355)$ with countercurrent air shear stress

The average film thickness of film flow $(\mathrm{Re}=355)$ with countercurrent air shear stress from CFD calculation, experimental data and theoretical euqation are presented in figure 5 in dimensionless form with the equations listed below:

$$
\delta^{+}=\frac{\delta w}{v}, \quad w=\sqrt{\frac{\tau_{c}}{\rho}}, \quad \tau_{c}=\frac{2}{3} \tau_{w}+\frac{1}{3} \tau_{i}
$$

where $v$ is the dynamic viscosity $\left(\mathrm{m}^{2} / \mathrm{s}\right), w$ is the shear stress velocity $(\mathrm{m} / \mathrm{s}), \tau_{\mathrm{c}}$ is the characteristic shear stress $\left(\mathrm{N} / \mathrm{m}^{2}\right), \tau_{\mathrm{w}}$ is the wall shear stress $\left(\mathrm{N} / \mathrm{m}^{2}\right)$. Compared to the results from the theoretical equation, CFD calculation has better prediction on $\delta^{+}$.

Average film thicnkness only reveals a small portion of film flow characteristics. PDF of film flow is a better variable to reflect more information on the film flow behavior, which is defined as follows:

$$
\begin{gathered}
F(\delta)=\frac{N u m_{i=1}^{n}\left(\delta_{i}<\delta\right)}{n} \\
P D F(\delta)=\frac{d F(\delta)}{d \delta}
\end{gathered}
$$

Where $F(\delta)$ is the probability distribution function and $N u m_{i=1}^{n}\left(\delta_{i}<\delta\right)$ represents number of the test data when the test data is less than $\delta$.

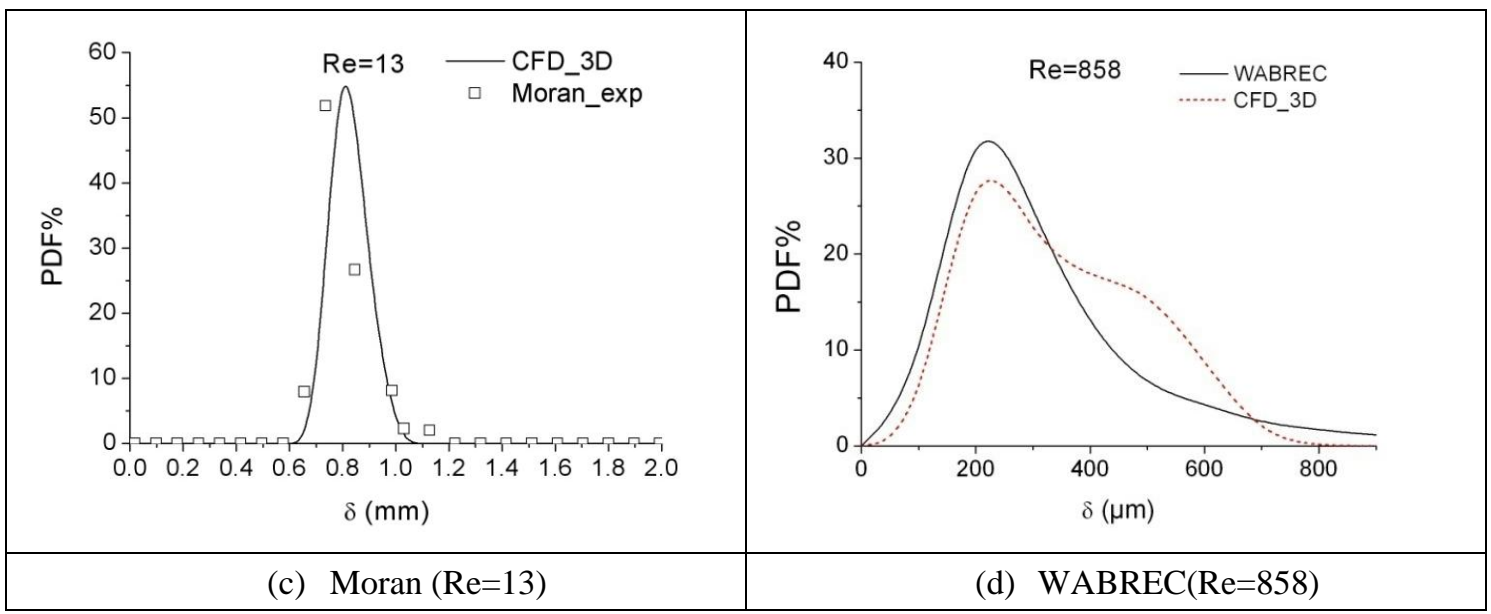


Figure 6 show the calculated PDF of film flow, which achieves reasonable agreement with the experimental data. As for the film flow with Reynolds number at 858, the heap waves appear.(Yu et.al.,(2012)). It cannot be captured by the simulation due to its complex structure, which explains the deviation of PDF profile between the simulation and the experiment. Nevertheless, there is no heap wave in film flow at low Reynolds number. Hence, the simulation agrees well with Moran's experimental data $(\mathrm{Re}=13)$.

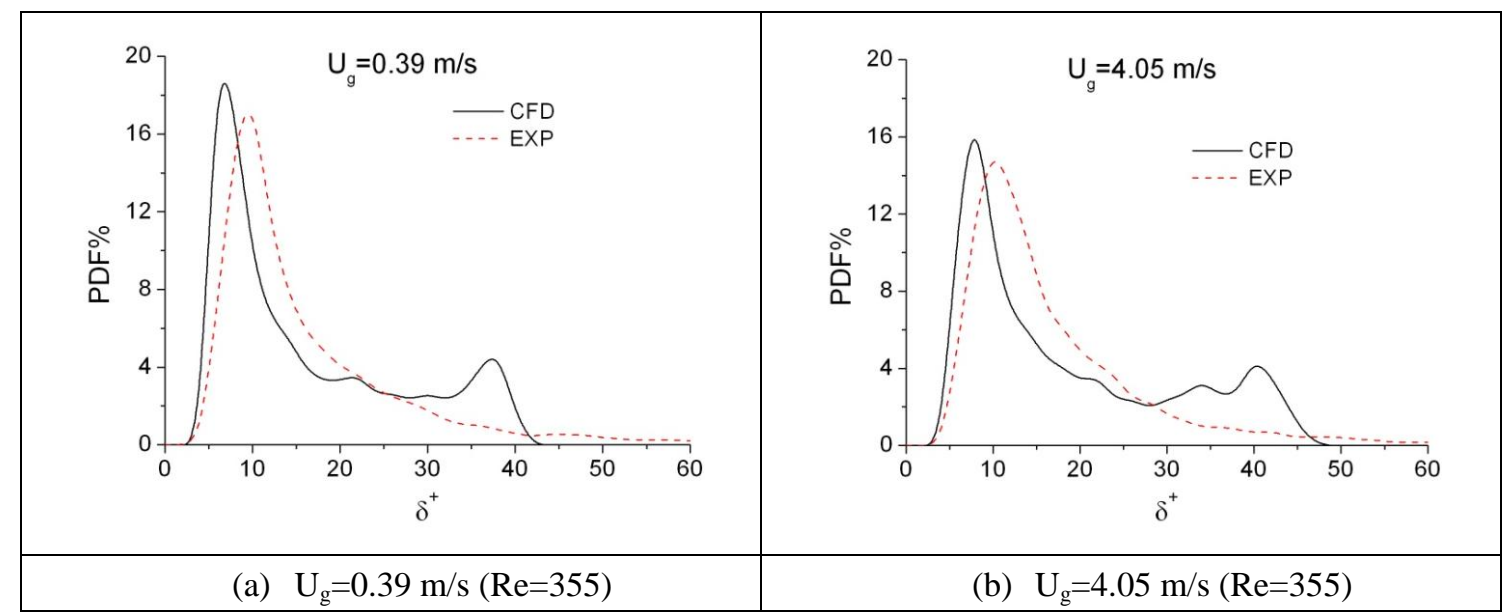

Figure 7 PDF(Probability Density Function) of film flow with counter current air flow

The calculated PDF of film flow with countercurrent air flow also achieved good agreement with the experimental data (figure 7). The deviation is due to insufficient test data. As we know, PDF is a statistic variable which needs huge amount of data. Insufficient data could lead to a distortion of the PDF curve. The capacity of the calculated data is restrained by its considerable computational cost.

\subsection{Film Velocity}

Given the difficulties in measuring the velocity of film flow, CFD method provides us a promising way to get a better understanding of the flow behavior. Figure 8 shows the calculated surface velocity distribution, the shape of which represents the scale of the film thickness and the color of which represents the scale of the surface velocity. It can be observed that the higher solitary wave is of higher surface velocity. The simulation also suggested that the larger solitary waves which are of greater surface velocity will merge with smaller ones as soon as they catch up with them. The similar film flow behavior is observed experimentally. 


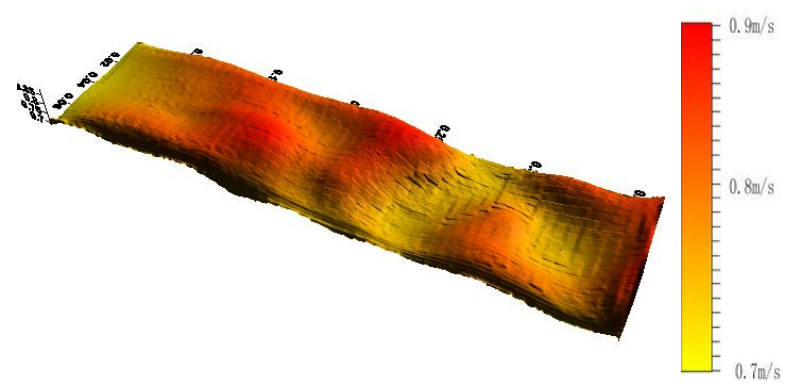

Figure 8 Three-dimensional sketch of velocity distribution of surface wave

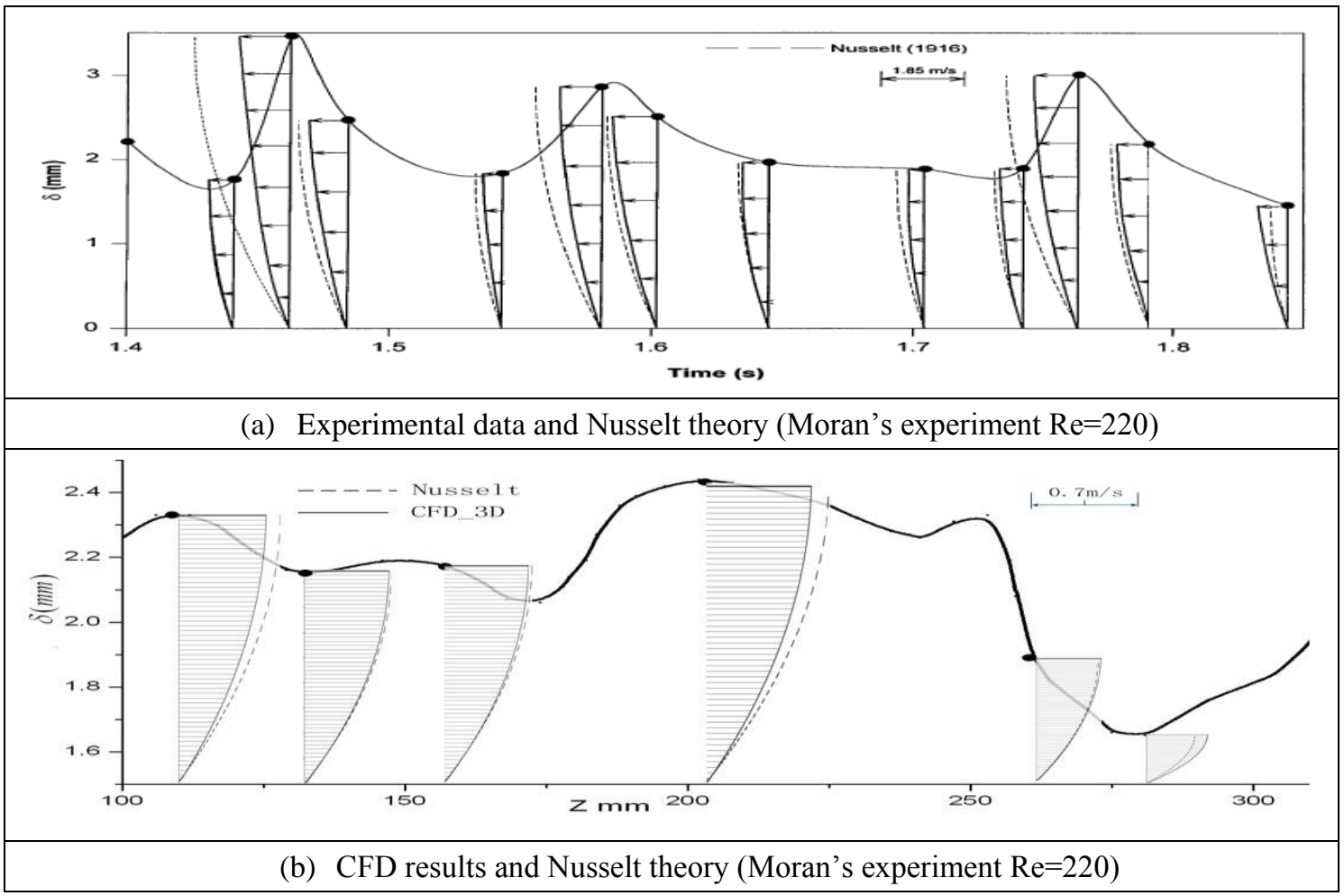

Figure 9 Instantaneous velocity distributions

Moran measured the velocity distributions inside the film flow and compared them with Nusselt theory (figure9a). This study compared the calculated velocity distribution with Nusselt theory as well (figure9b). At the wave crest, Nusselt theory over predicts the film velocity obtained either numerically or experimentally. The maximum deviation reaches $15 \%$. On the contrary, Nusselt theory underestimates the film velocity at the wave trough. It can be understood because the velocity distribution is effected by many factors such as air shear stress, transverse flow inside film and the structure of the solitary wave, which are all eliminated in Nusselt theory. Therefore, the indirect comparisons between the experimental measurement and the CFD results further validate the CFD model in this study.

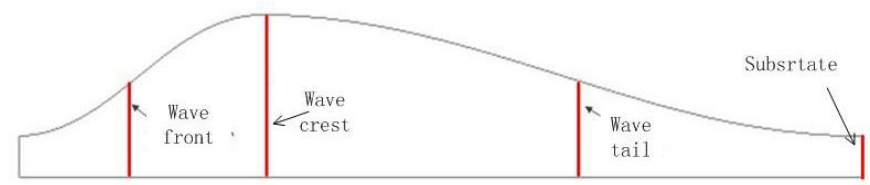

Figure 10 Sketch of four typical positions 


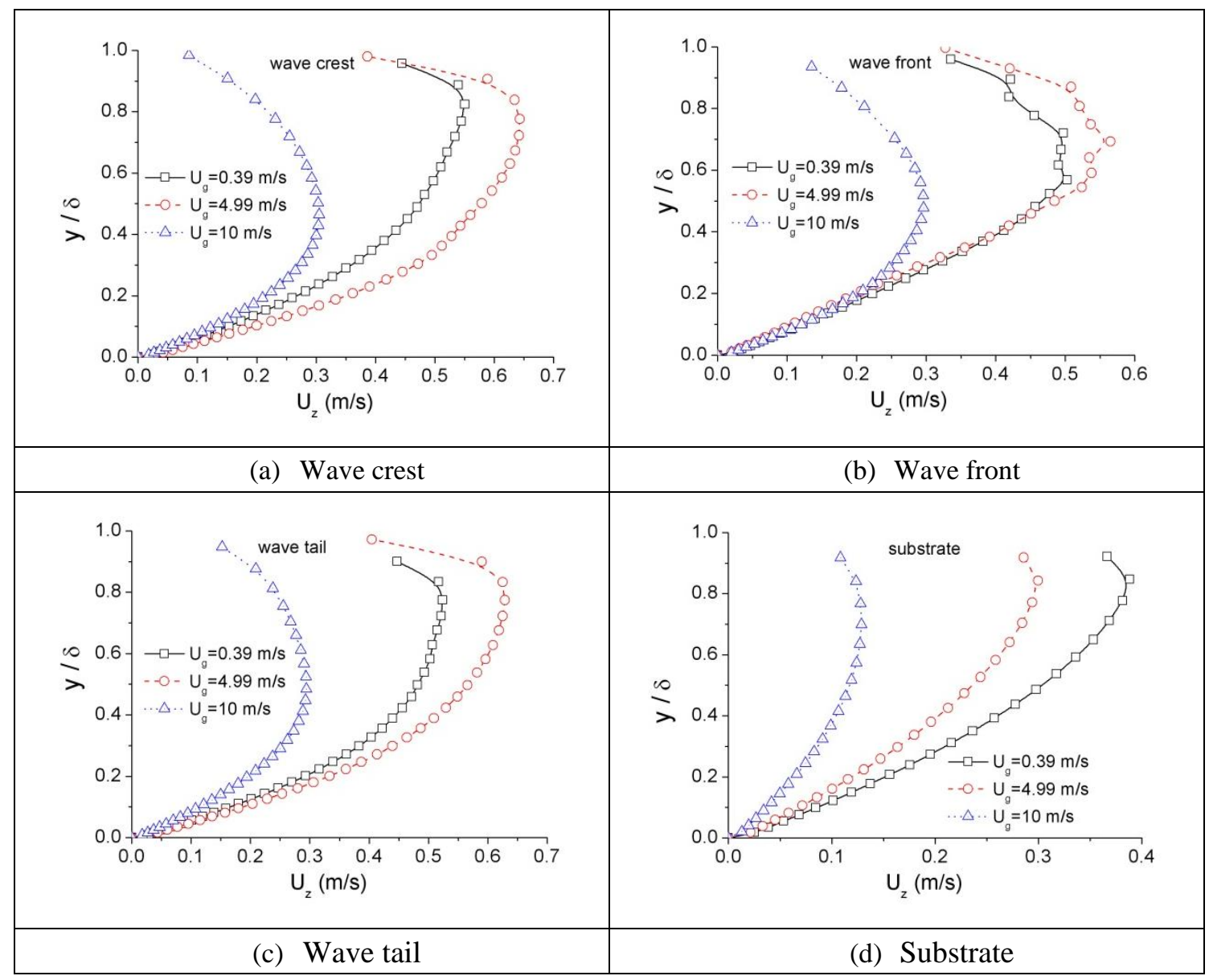

Figure 11 Velocity distributions inside the falling film with countercurrent air action

This study also performs numerical simulations on film flow with downward current and countercurrent air velocity. The air velocity is $0.39,0.499$ and $10 \mathrm{~m} / \mathrm{s}$ respectively. In PCCS, the maximum air velocity can reach about $5 \mathrm{~m} / \mathrm{s}$ due to the natural circulation. This study expands the range of air velocity numerically to study the mechanism of the film flow. With counter current air action, the air action has greater effects on the surface velocity distribution around wave crest since the greatest air shear stress is imposed there. As the air velocity increases from $0.39 \mathrm{~m} / \mathrm{s}$ to $4.99 \mathrm{~m} / \mathrm{s}$, the average surface velocity only decreases from $0.23 \mathrm{~m} / \mathrm{s}$ to $0.22 \mathrm{~m} / \mathrm{s}$. As the air velocity continues increasing to $10 \mathrm{~m} / \mathrm{s}$, the average surface velocity has a sharp decrease to $0.08 \mathrm{~m} / \mathrm{s}$. When the downward current air velocity is $0.39 \mathrm{~m} / \mathrm{s}, 4.99 \mathrm{~m} / \mathrm{s}$ and $10 \mathrm{~m} / \mathrm{s}$, the average film surface velocity reaches $0.23 \mathrm{~m} / \mathrm{s}, 0.26 \mathrm{~m} / \mathrm{s}$ and $0.28 \mathrm{~m} / \mathrm{s}$ respectively. Downward current air action seems to have less significant effect on the surface wave velocity. Figure 11 presents the velocity distributions inside film flow with countercurrent air action at four typical positions, which is the wave crest, wave front, wave tail and film substrate respectively (figure10). The maximum velocity appears at $70 \%$ film thickness under the free surface, which agrees well with the experimental results reported by Yu's et.al., (2006). Figure 12 presents the velocity distributions inside the film with downward current air action at four typical positions. The effect of air shear stress is focused on the velocity distribution in the vicinity of the free surface. The velocity distribution near the plate is hardly influenced. 


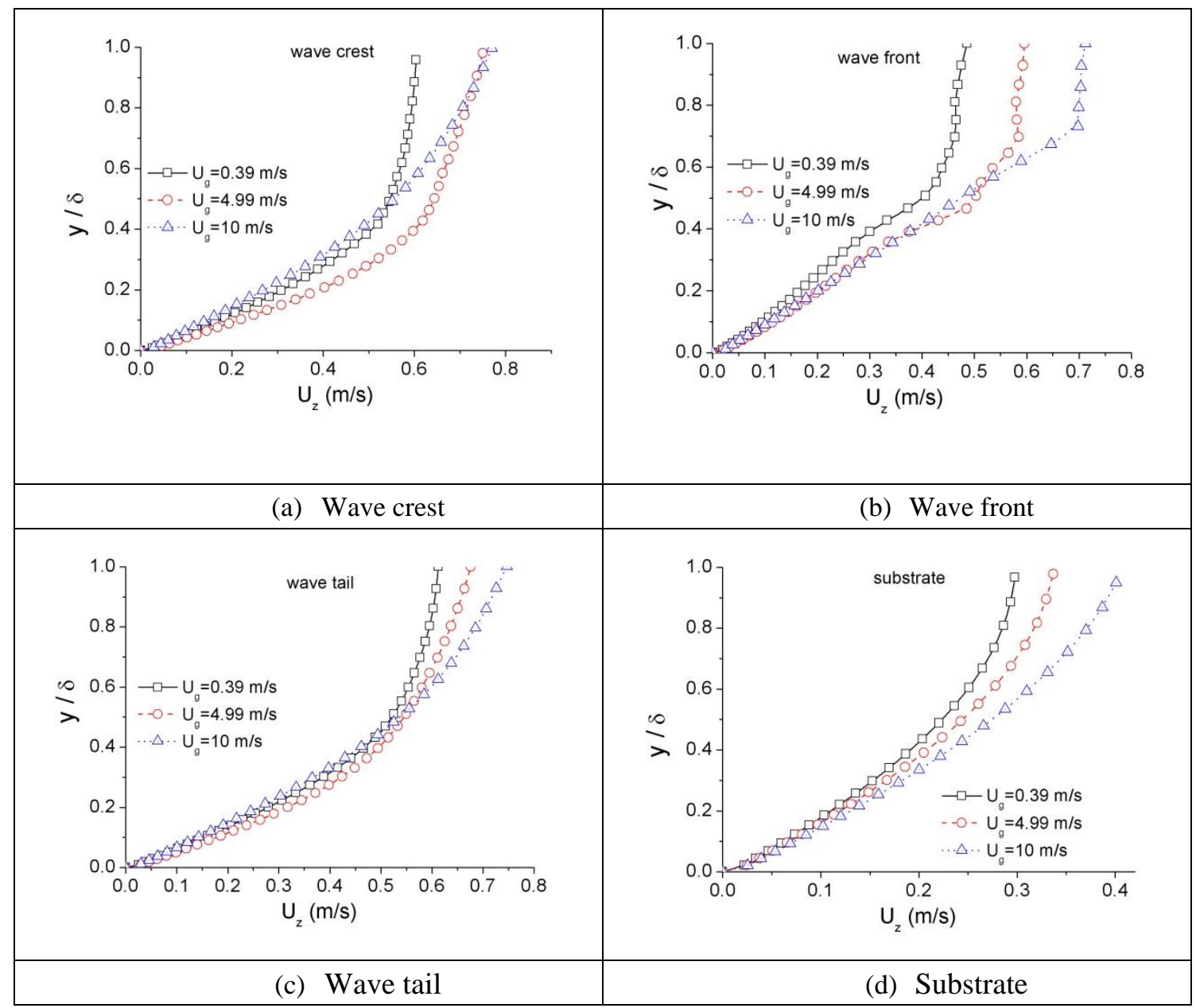

Figure 12 Velocity distributions inside falling film with downward current air action

\subsection{Wall Shear Stress}

When film flow is fully developed, a force balance between wall shear stress $\tau_{\mathrm{w}}$ and a component of the gravity $\rho g \delta \sin \phi$ is achieved. The variation trends of film thickness $\delta$ and wall shear stress $\tau_{\mathrm{w}}$ are supposed be consistent. In figure 13, some simulations of the instantaneous wall shear stress and film thickness of film flow at Reynolds number 13 and 220 in Moran's experiment are presented. The variation trends of $\delta$ and $\tau_{\mathrm{w}}$ are consistent when Reynolds number is low $(\operatorname{Re}=13)$. The synchronism between the film thickness and the wall shear stress gets weaker when film flow is at higher Reynolds number $(\operatorname{Re}=220)$. The peak of the wall shear stress appears prior to the peak of the film thickness a bit. This phenomenon is also observed by Miya's, et.al., (1971), Wasden and Dukler (1989) and Moran, et.al., (2002) experimentally. 


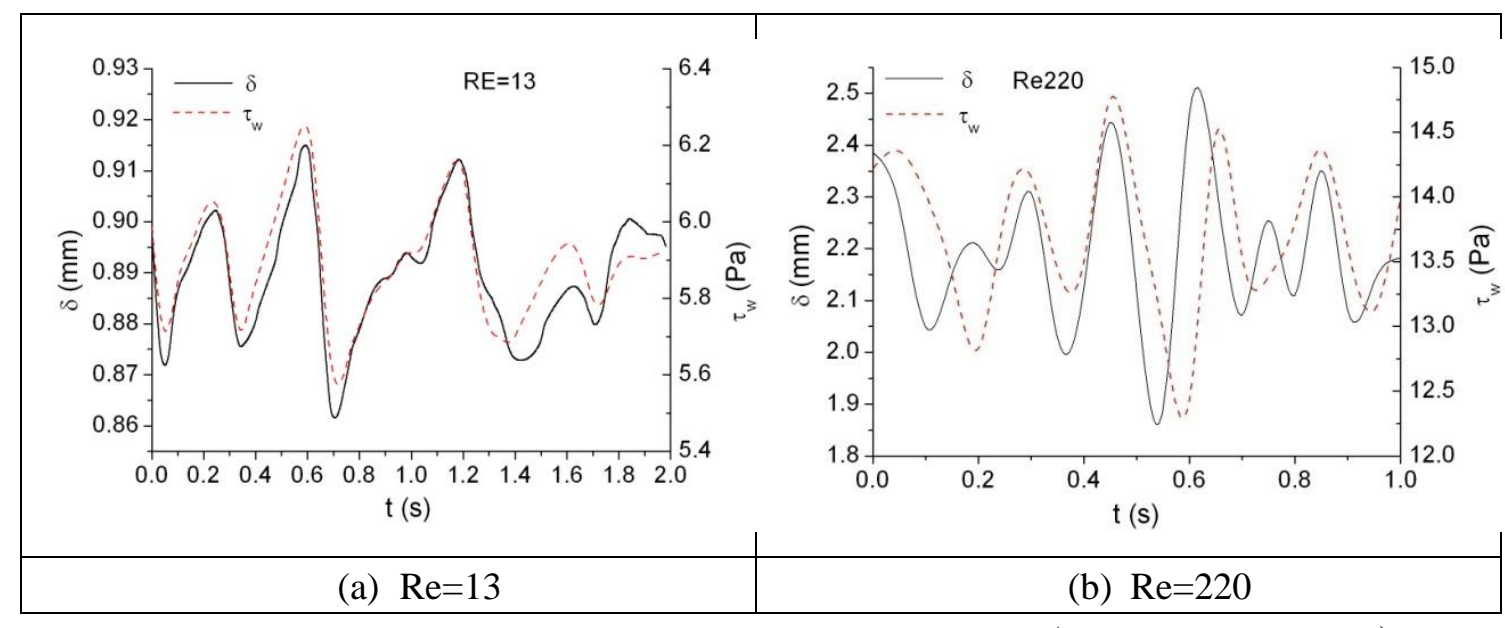

Figure13: Instantaneous wall shear stress and film thickness (Moran's experiment)

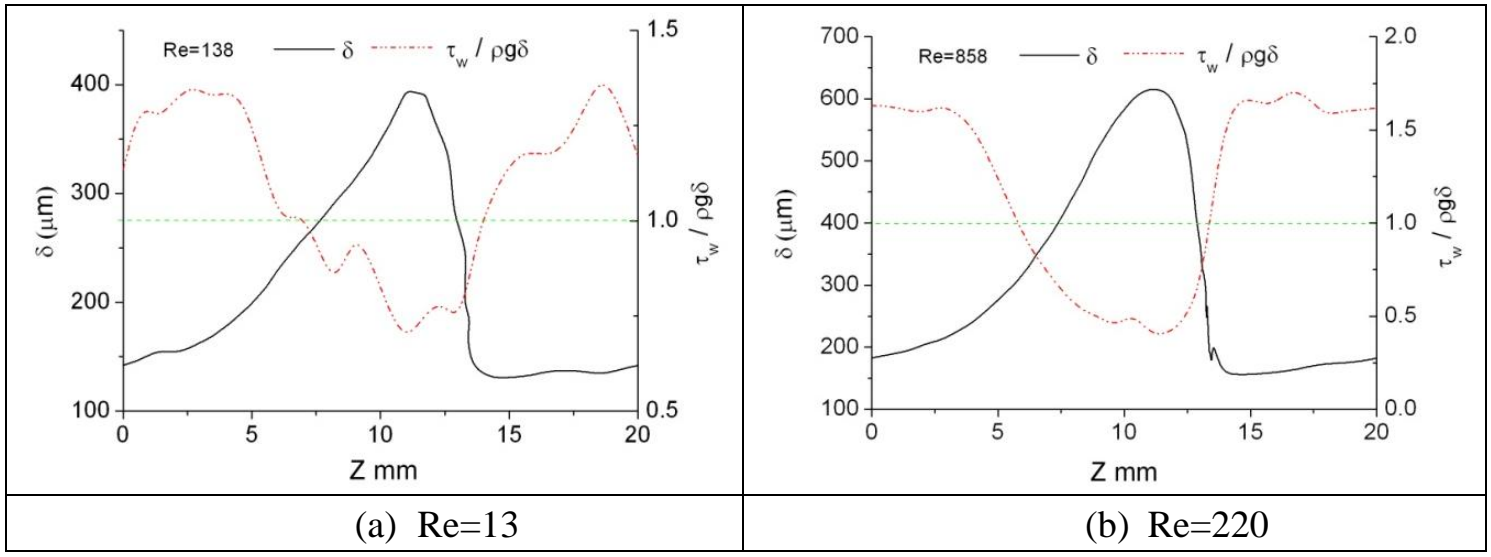

Figure14: Instantaneous wall shear stress in a solitary wave (WABREC experiment)

The dimensionless wall shear stress $\tau_{\mathrm{w}} / \rho \mathrm{g} \delta$ may be helpful to explain the flow behavior in the solitary wave (figure14). When $\tau_{\mathrm{w}} / \operatorname{\rho g} \delta<1$, it suggests that the gravity is greater than the wall shear stress, which leads to the acceleration of the fluid. When $\tau_{\mathrm{w}} / \rho g \delta>1$, it suggests that the gravity is smaller than the wall shear stress, which leads to the deceleration of the fluid. It is quite clear that the fluid is accelerated right under the wave crest and decelerated elsewhere. The wall shear stress is $30 \%$ smaller than the gravity under the wave crest at $\mathrm{Re}=138$ and $60 \%$ at $\mathrm{Re}=858$. It agrees well with $\mathrm{Yu}$ et.al.,(1995)'s numerical research. The acceleration and deceleration of the fluid inside the film become stronger with the increase of Reynolds number. The analysis above indicates that the film flow is not in a steady state of uniform motion but in a semi steady state of alternative acceleration and deceleration.

\subsection{Film Breakup}

During the later stage of an accident, the mass flux of the film flow decreases due to the lower water level in the storage tank. Continuous film flow begins to break up to rivulet flow or drip flow, which leads to appearance of a dry patch and then the heat transfer deterioration on the containment. The dimensionless minimum mass flux of film flow which can keep the film flow from breakup is called MWR (Minimum Wetting Rate: $\Delta_{\min }$ ). The dimensionless film thickness corresponding to MWR is called MLFT (Minimum Liquid Film Thickness: $\Gamma_{\min }$ ). Due to the complex mechanism of film breakup, this paper only discusses the breakup 
simulation of isothermal free falling film flow without shear stress on the water-air interface. Current theoretical analyses on breakup of free falling film are mainly based on the equilibrium model of stagnation point or the least-energy principle of rivulet flow. Some theoretical correlations are listed in table 3 . The correlations indicate that the contact angle between fluid and wall plays significant role on $\Delta_{\min }$ and $\Gamma_{\min }$.

Table 3 Theoretical correlations of $\Delta_{\min }$ and $\Gamma_{\min }$ for free falling film flow

\begin{tabular}{|c|c|c|}
\hline Researcher & Correlation & Assumptions and errors \\
\hline $\begin{array}{l}\text { Hartely and Murgatroyd } \\
\qquad(1964)\end{array}$ & $\begin{array}{l}\Delta_{\min }=(1-\cos \theta)^{1 / 5} \\
\Gamma_{\min }=1.693 \Delta_{\min }^{3}\end{array}$ & $\begin{array}{l}\text { Based on equilibrium model of stagnation point and } \\
\text { zero-order velocity assumption. } \Gamma_{\min } \text { is obtained from Nusselt } \\
\text { theory. } \Delta_{\min } \text { overestimates the experimental data by } 30 \% . \Gamma_{\min } \\
\text { overestimates the experimental data by } 70 \% \text {. }\end{array}$ \\
\hline $\begin{array}{l}\text { Hobler } \\
\text { (1964) }\end{array}$ & $\begin{array}{c}\Delta_{\min }=(3 / 2)^{1 / 5}(1-\cos \theta)^{1 / 5} \\
\Gamma_{\min }=1.693 \Delta_{\min }^{3}\end{array}$ & $\begin{array}{l}\text { Based on least-energy principle of rivulet flow and zero-order } \\
\text { velocity assumption. } \Gamma_{\min } \text { is obtained from Nusselt theory. } \\
\Delta_{\min } \text { overestimates the experimental data by } 42 \% \text {. }\end{array}$ \\
\hline $\begin{array}{l}\text { Doniec } \\
(1991)\end{array}$ & $\begin{array}{c}\Delta_{\min }=(3 / 7)^{1 / 5}(1-\cos \theta)^{1 / 5} \\
\Gamma_{\min }=1.693 \Delta_{\min }^{3}\end{array}$ & $\begin{array}{l}\text { Based on least-energy principle of rivulet flow and zero-order } \\
\text { velocity assumption. The profile of rivulet flow is determined } \\
\text { by zero-order velocity. } \Gamma_{\min } \text { is obtained from Nusselt theory. } \\
\Delta_{\min } \text { overestimates the experimental data by } 30 \% . \Gamma_{\min } \\
\text { overestimates the experimental data by } 50 \% \text {. }\end{array}$ \\
\hline $\begin{array}{l}\text { EI-Genk and Saber } \\
\qquad(2001)\end{array}$ & $\begin{array}{c}\Delta_{\min }=(1-\cos \theta)^{0.22} \\
\Gamma_{\min }=0.67 \Delta_{\min }^{2.83}+0.26 \Delta^{9.51} \min \end{array}$ & $\begin{array}{l}\text { Based on equilibrium model of stagnation point and } \\
\text { two-dimensional velocity assumption. The profile of rivulet } \\
\text { flow is determined by two-dimensional velocity. } \Gamma_{\min } \text { is } \\
\text { obtained from two-dimensional velocity distribution. The } \\
\text { error between } \Delta_{\min } \text { and experimental data is } \pm 10 \sim 15 \% \text {. The } \\
\text { error between } \Gamma_{\min } \text { and experimental data is } \pm 20 \% \text {. }\end{array}$ \\
\hline
\end{tabular}

The same 3D model is applied to study the film breakup. The calculations begin from the continuous film flow. The mass flux of film flow is reduced gradually and slowly till the film breakup. As the film flow begins to breakup, the critical film thickness $\left(\delta_{\text {critical }}\right)$ and critical mass flux ( $\left.\Gamma_{\text {critical }}\right)$ is obtained. $\delta_{\text {critical }}$ and $\Gamma_{\text {critical }}$ can be presented in dimensionless form as $\Delta_{\min }$ and $\Gamma_{\min }$ with equation 37 and 38 .

$$
\begin{gathered}
\Delta_{\text {min }}=\delta_{\text {critical }}\left(\frac{\rho^{3} g^{2}}{15 \mu^{2} \sigma}\right)^{1 / 5} \\
\Gamma_{\text {min }}=\Gamma_{\text {critical }} /\left(\frac{\rho \mu \sigma^{3}}{g}\right)^{1 / 5}
\end{gathered}
$$

Figure 15 shows the simulation of film breakup, the color of which represents the scale of film thickness. The blue suggests that the film thickness is 0 . It is observed that the film breakup occurs on the plate where the film thickness is smaller at first. A dry patch begins to appear and then expands to a larger one. The parabolic profile of the dry patch agrees well with the experimental observations. After a short period of time, another patch appears. With the expansion of both dry patches, a rivulet flow is formed.
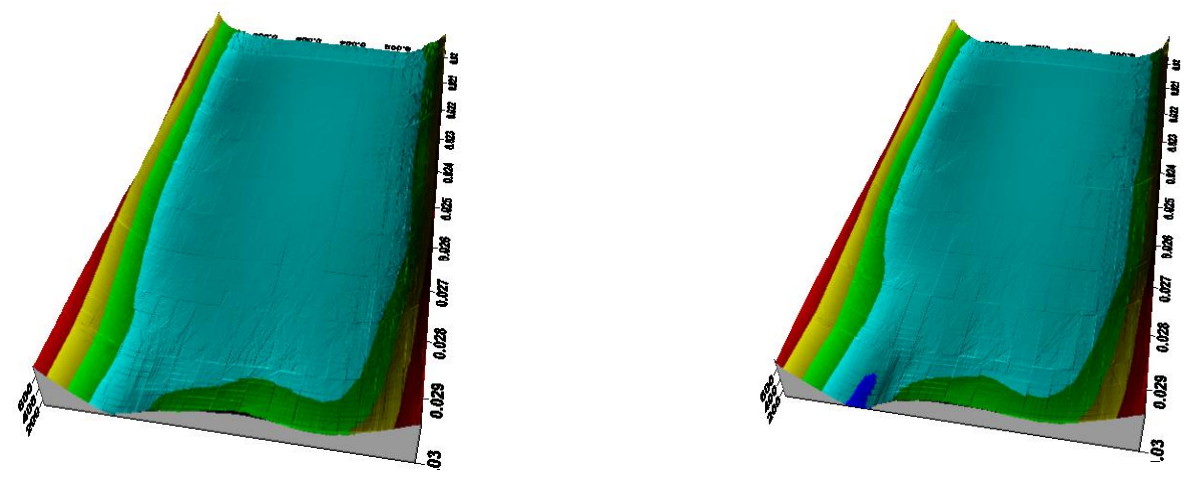
(a) $\mathrm{t}=0 \mathrm{~s}$

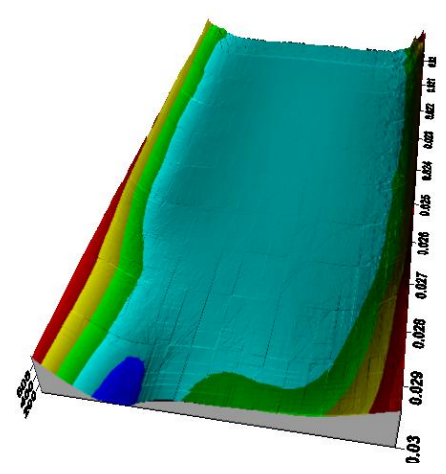

(c) $\mathrm{t}=0.006 \mathrm{~s}$

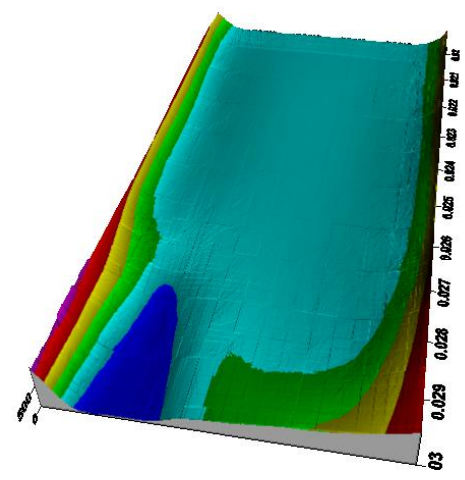

(e) $\mathrm{t}=0.012 \mathrm{~s}$

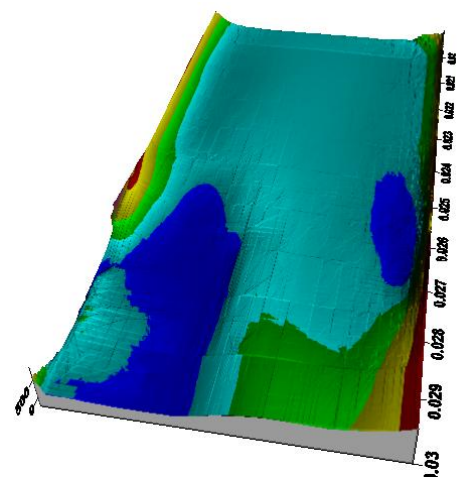

(g) $\mathrm{t}=0.018 \mathrm{~s}$ (b) $\mathrm{t}=0.003 \mathrm{~s}$

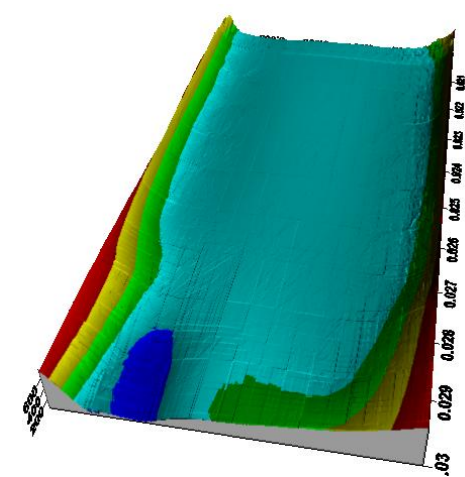

(d) $\mathrm{t}=0.009 \mathrm{~s}$

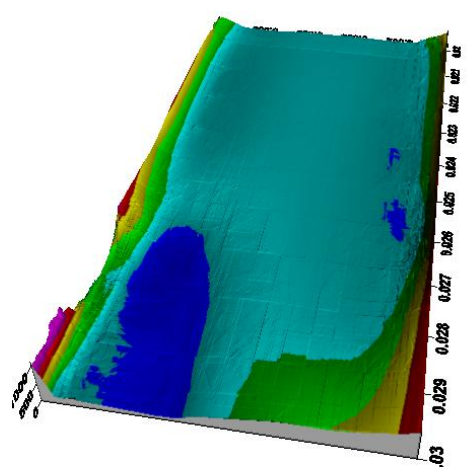

(f) $\mathrm{t}=0.015 \mathrm{~s}$

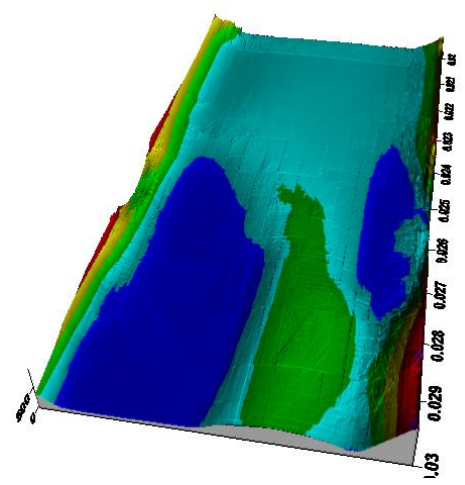

(h) $\mathrm{t}=0.021 \mathrm{~s}$

Figure15 three-dimensional snapshot of free falling film break up

Since the experimental investigations of film breakup on flat plate are rare, figure 16 compares the calculated $\Delta_{\min }$ and $\Gamma_{\min }$ with the correlations in table 3 and Ponter et.al., (1967)'s and Munakata et.al., (1975)'s experimental studies which are both conducted on tubes. 


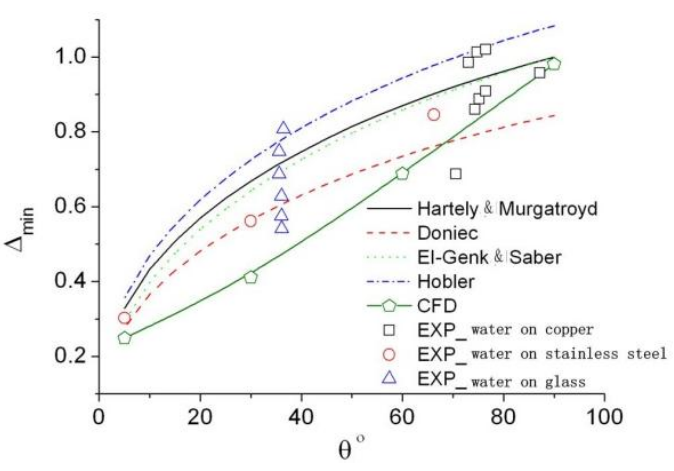

(a) $\operatorname{MLFT}\left(\Delta_{\min }\right)$

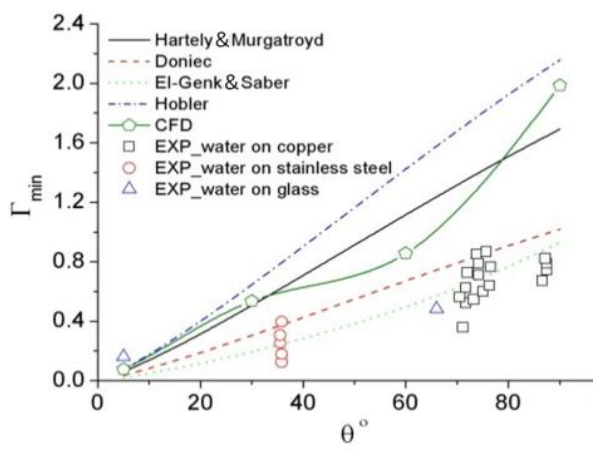

(b) $\operatorname{MWR}\left(\Gamma_{\min }\right)$

Figure 16 MLFT and MWR of free falling film flow

$\Delta_{\min }$ in CFD calculation underestimates the experimental value. On one hand, it is because that the restricted computational domain and the boundary condition restrain the film breakup. On the other hand, the test data is from the experiments conducted in small tubes. In a practical application, $\Gamma_{\min }$ is the key parameter used to control the mass flux of film flow. It is worth mentioning that $\Gamma_{\min }$ of CFD calculation not only envelops the experimental data but also has a reasonable prediction. The numerical model proposed in this paper is not so efficient in calculating $\Gamma_{\min }$ because of the computational cost. But it is a promising way to reveal the mechanism of film breakup since it provides much more detailed information on flow field than other theoretical models.

\section{Conclusions}

CFD simulations of film flow with and without water-air shear stress are performed in this paper. A numerical model is established based on the characteristic of film flow. A source term is implanted into the Navier-Stokes equations to take into account the effect of water-air shear stress. The validation is developed based on the experimental results from both the test rigs built by the author and the experimental results reported by other researchers. Film average thickness, PDF of film thickness, wave surface velocity, film velocity and wall shear stress are analyzed to study the film flow behavior. Several conclusions are drawn from the discussions:

1. The two-dimensional simulations failed to predict the surface wave due to constrain of the boundary conditions and neglect of the surface tension. The three-dimensional simulations can reproduce the surface wave and predict the flow behavior in good agreement with the experimental data. However, some heap waves which appear in film flow at high Reynolds number are not fully captured.

2. This paper compared calculated velocity distribution of film flow with the measurement indirectly. The good agreement further validates the numerical model. The results also confirmed that Nusselt theory underestimates the film velocity of the wave crest while it overestimates the film velocity of wave trough.

3. The air shear stress plays significant role on velocity distribution close to the free surface. The maximum velocity appears at $70 \%$ film thickness under the free surface with counter current air shear stress, which could cause two vortices inside the solitary wave.

4. The asynchronous variation trends of film thickness and wall shear stress suggests that the film fluid is not in a steady state of uniform motion but in an alternative state of 
acceleration and deceleration. The film fluid is accelerated right under the wave crest and decelerated elsewhere. The acceleration and deceleration of film fluid become stronger with the increase of Reynolds number.

5. MWR (Minimum Wetting Rate: $\Delta_{\min }$ ) and MLFT (Minimum Liquid Film Thickness: $\Gamma_{\min }$ ) is obtained through film breakup simulation. The model in this study ought to be profitable to study the mechanism of film breakup.

\section{Acknowledgement}

A support from National Key Projects 2010ZX06002-005 is gratefully acknowledged. This work is also supported by the U.S. Department of Energy, Basic Energy Sciences, Office of Science, under contract \# DE-AC02-06CH11357.

\section{Reference}

Nusselt N, Die Oberflachenkondensation des Wasserdampfes,Zeit.Ver.D.Ing.[J]60:541-569, 1916

Kheshgi H.S., Scriven L.E., Disturbed Film Flow on a Vertical Plate [J]. Physics of Fluids, 1987, 30:990.

Maron D.M., Brauner N., Hewitt G.F., Flow Patterns in Wavy Thin Films: Numerical Simulation [J]. International Communications in Heat and Mass Transfer, 1989, 16(5):655-666.

Stuhlträger E., Miyara A., Uehara H., Flow Dynamics and Heat Transfer of a Condensate Film on a Vertical Wall-II. Flow Dynamics and Heat Transfer [J], International Journal of Heat and Mass Transfer, 1995, 38(15):2715-2722.

Serifi K, Malamataris N.A., Bontozoglou V., Transient Flow and Heat Transfer Phenomena in Inclined Wavy Films [J]. International Journal of Thermal Sciences, 2004, 43(8):761-767.

Tomoaki K., Chiaki K., Numerical Simulation of Oscillatory Falling Liquid Film Flows [J]. Fusion Engineering and Design, 2003, 65(3):387-392.

Miyara A., Numerical Analysis on Heat Transfer of Falling Liquid Films with Interfacial Waves [C]. Heat Transfer Proceedings of 11th IHTC, Kyongju, Korea, 1998, 57-62.

Miyara A., Numerical Analysis on Flow Dynamics and Heat Transfer of Falling Liquid Films with Interfacial Waves [J]. Heat and Mass Transfer, 1999, 35(4):298-306.

Miyara A., Numerical Simulation of Wavy Liquid Film Flowing Down on a Vertical Wall and an Inclined Wall [J], International Journal of Thermal Sciences, 2000, 39(9-11):1015-1027.

Jayanti S., Hewitt G.F., Hydrodynamics and Heat Transfer of Wavy Thin Film Flow [J], International Journal of Heat and Mass Transfer, 1997a, 40(1):179-190.

Jayanti S., Hewitt G.F., Hydrodynamics and Heat Transfer in Wavy Annular Gas-Liquid Flow: Computational Fluid Dynamics Study [J]. International Journal of Heat and Mass Transfer, 1997b, 40(10): 2445-2460.

Gao D., Morley N.B., Dhir V., Numerical Simulation of Wavy Falling Film Flow Using VOF Method [J], Journal of Computational Physics, 2003, 192 :624.

Sutalo I.D., Bui A., Rudman M., The Flow of Non-Newtonian Fluids down Inclines [J]. Journal of Non-newtonian Fluid Mechanics, 2006, (136):64-75. 
Yoshida H., Tamai H., Ohnuki A., et al., Current Status of Thermal-Hydraulic Feasibility Project for Reduced-Moderation Water Reactor (2) -Development of Two-phase Flow Simulation Code with Advanced Interface Tracking Method [J]. Nuclear Engineering and Technology, 2006, Special Issue on ICAPP'05, 38(2):119-128.

Haeria S., Hashemabadi S.H., Three Dimensional CFD Simulation and Experimental Study of Power Law Fluid Spreading on Inclined Plates [J]. International Communications in Heat and Mass Transfer, 2008, 35(8):1041-1047.

Lakehal D., Fulgosi M., Yadigaroglu G., Banerjee S., Direct Numerical Simulation of Turbulent Heat Transfer across a Mobile, Sheared Gas-liquid Interface [J]. Journal of Heat Transfer, 2003, 125: 1129-1140.

Brackbill J.U., Kothe D.B., Zemach C., A Continuum Method for Modelling Surface Tension [J]. Journal of Computational Physics, 1992, 100:335-354.

Iliuta I, Thyrion F.C., Bolle L., Giot M., Comparison of Hydrodynamic Parameters for Countercurrent and Cocurrent Flow Through Packed Beds [J]. Chemical Engineering \& Technology, 1997, 20:171-181.

Brauner N., Maron D.M., Characteristics of Inclined Thin Films, Waviness and the Associated Mass transfer [J]. International Journal of Heat and Mass Transfer, 1982, 25(1):99-110.

Stephan M., Mayinger F., Experimental and Analytical Study of Counter-current Flow Limitation in Vertical Gas/liquid Flows [J]. Chemical engineering \& technology, 1992, 15:1-62.

Ansys CFX 10.0:Manual[M].ANSYS,Inc,2005.

Yu Y.Q., Wei S.J., Yang Y.H., Cheng X.," Experimental study of water film falling and spreading on a large vertical plate", Progress in Nuclear Energy, 54:22-28, 2012

YQ Yu., X Cheng, Experimental study of water film flow on large vertical and inclined flat plate, Progress in Nuclear Energy, 77:176 186, 2014

Moran K., Inumaru J., Kawaji M., Instantaneous Hydrodynamics of a Laminar Wavy Liquid Film [J]. International Journal of Multiphase Flow, 2002, 28:731-755.

Yu L.M., Zeng A.W., Yu K.T., Effect of Interfacial Velocity Fluctuations on the Enhancement of the Mass-transfer Process in Falling Film Flow [J]. Industrial \& engineering chemistry Research, 2006, 45(3):1201-1210.

Miya M., Woodmansee D., Hanratty T.J., A model for Roll Waves in Gas-liquid Flow [J]. Chemical Engineering Science, 1971, 26:1915-1931.

Wasden F.K., Dukler A.E., Numerical Investigation of Large Wave Interactions on Free Falling Films [J]. International Journal of Multiphase Flow, 1989, 15:357-370

Yu L.Q., Wasden F.K., Dukler A.E., Balakotaiah V., Nonlinear Evolution of Waves on Falling Films at High Reynolds Numbers [J]. Physics of Fluids, 1995, 7:1886-1902.

Hartely D.E., Murgatroyd W., Criteria for the Break-up of Thin Liquid Layers Flowing Isothermally over Solid Surface [J]. International Journal of Heat and Mass Transfer, 1964, 7:1003.

Hobler T., Minimum Surface Wetting [J]. Chemia Stosow, 1964, 2B:145

Doniec A., Laminar Flow of a Liquid Rivulet down a Vertical Solid Surface [J].The Canadian Journal of Chemical Engineering, 1991, 69(1):198-202.

El-Genk M.S., Saber H.H., Minimum Thickness of a Flowing down Liquid Film on a Vertical Surface [J]. International Journal of Heat and Mass Transfer, 2001,44:2809. 
Ponter B., Davies G.A., Ross T.K, Thornley P.G., The Influence of Mass Transfer on Liquid Film Breakdown [J], International Journal of Heat and Mass Transfer, 1967, 10:349-359.

Munakata T., Watanabe K., Miyashita K., Minimum Wetting Rate on Wetted-wall Column [J]. Journal of Chemical Engineering of Japan. 1975,8(6):440-444

Adrian Tentner, Prasad Vegendla and Elia Merzari. Computational Fluid Dynamics Modeling of Two-phase Boiling Flow and Critical Heat Flux, July 2014, ICONE22-30844, Prague, Czech Republic.

Vegendla, S.N.P., Messig, D., Weise, S., Hasse, C. A FLAMELET based time scale analysis of a high pressure gasifier. Energy and Fuels, 2011a, 25, pp: 3892-3899.

Vegendla, S.N.P., Heynderickx, G.J., Marin, G.B. Probability density function simulation of turbulent reactive gas-solid flow in a FCC riser. AIChE, 2012, 58, pp: 268-284.

Vegendla, S.N.P., Heynderickx, G.J., Marin, G.B. Comparison of Eulerian-Lagrangian and Eulerian-Eulerian approach for solids side inlet for dilute gas-solid flows. Computers and Chemical Engineering, 2011b, 35(7), pp: 1192-1199. 